\title{
Effect of left bundle branch block on diastolic function in dilated cardiomyopathy
}

\author{
H B Xiao, C H Lee, D G Gibson
}

\begin{abstract}
Objective-To assess the diastolic effect of left bundle branch block in patients with dilated cardiomyopathy.

Design-Retrospective study of $M$ mode and Doppler echocardiograms along with electrocardiogram and phonocardiogram.
\end{abstract}

Setting-Tertiary referral cardiac centre.

Patient participants-Fifty two patients with dilated cardiomyopathy, all with functional mitral regurgitation. Twelve with left bundle branch block (group 1) were compared with 40 without (group 2).

Results-Mean (SD) age 60 (15) v 55 (18) years, left ventricular end diastolic dimension $72(9) v 70(7) \mathrm{mm}$, and heart rate 88 (15) $v 84$ (15) beats/min were similar in both groups. In patients with left bundle branch block the electromechanical delay, 50 (20) $v 70(20) \mathrm{ms}$, was shorter $(p<0.05)$ whereas the preejection contraction time, measured from the onset of mitral regurgitation to that of aortic ejection, 130 (40) $v 70$ (20) ms ( $p<0.01)$, and left ventricular relaxation time, $A_{2}$ to the end of mitral regurgitation, 130 (30) $v 80$ (30) ms (p < 0.01), were both prolonged. Ejection time itself was similar, 230 (40) $v 235$ (40) ms. Thus the overall duration of mitral regurgitation was increased (495 (90) $v 390(60) \mathrm{ms}$ $(p<0.01)$ ), which made filling time shorter (190 (45) $v 325(90) \mathrm{ms}(\mathrm{p}<0.01))$. In patients with left bundle branch block, unlike those without, contraction and relaxation times both shortened as $\mathbf{R R}$ interval fell; this made the duration of mitral regurgitation more sensitive to heart rate. Filling time was less than $200 \mathrm{~ms}$ in eight out of 12 patients with left bundle branch block and four out of 40 patients without ( $p<0.001)$.

Conclusion-Left bundle branch block prolongs rather than delays mitral regurgitation by increasing pre-ejection and relaxation times. This directly impairs diastolic function by shortening the time available for the left ventricule to fill to an extent likely to limit stroke volume.

In patients with dilated cardiomyopathy, systolic function is already impaired and this is aggravated when left bundle branch block is present. ${ }^{1-3}$ But whether left bundle branch block, which is not uncommon in these patients, also affects diastolic performance has not been studied. We have recently noted that in some patients with dilated cardiomyopathy functional mitral regurgitation is prolonged to such an extent that it interferes with diastolic function by shortening left ventricular filling time. ${ }^{4}$ This study, therefore, was designed to investigate whether left bundle branch block aggravated this effect of functional mitral regurgitation.

\section{Patients and methods}

The records of 52 cases with uniform left ventricular cavity dilatation (left ventricular end diastolic dimension $>6.5 \mathrm{~cm}$ ) and reduced shortening fraction $(<15 \%)$ were assessed. All of them had functional mitral regurgitation detected by continuous wave Doppler recordings. Table 1 shows the clinical details.

Twenty two underwent catheterisation and 10 were found to have underlying coronary disease by coronary arteriography; the others all had dilated cardiomyopathy clinically. None had hypertension and all but four (in atrial fibrillation) were in sinus rhythm. All were taking diuretics; 20 were also taking captopril. Of the 52 patients 12 had left bundle branch lock (group 1) and 40 did not (group 2). Seven in Group 1 and 17 in Group 2 also had tricuspid regurgitation. Criteria for left bundle branch block included QRS duration increased $\geqslant 120 \mathrm{~ms}$, q waves absent but wide slurred $R$ waves present in V5 and V6, monophasic QS or rS waves present in V1 and V2, and QRS axis deviated to - 30 degrees or further to the left.

$M$ mode echocardiograms obtained with ATL equipment and a 3.5 MHz transducer at the level of the tips of the papillary muscles were recorded with a simultaneous phonocardiogram to show the second heart sound and with lead II of the electrocardiogram. Clear endocardial echoes of the left side of the interventricular septum and left ventricular posterior wall were obtained in all patients. We used a $2.5 \mathrm{MHz}$ transducer to record continuous wave Doppler traces made with a Doptek system, again along with a phonocardiogram and an electrocardiogram. All records were printed photographically at a speed of $100 \mathrm{~m} / \mathrm{s}$.

On the $M$ mode echocardiograms we measured the left ventricular end diastolic dimension at the onset of the QRS complex of 
Table 1 Clinical data

\begin{tabular}{lll}
\hline & $\begin{array}{l}\text { Patients with left } \\
\text { bundle branch block }\end{array}$ & $\begin{array}{l}\text { Patients without left } \\
\text { bundle branch block }\end{array}$ \\
\hline Total no of patients & 12 & 40 \\
Age (SD) (y) & $60(15)$ & $55(18)$ \\
Left ventricular end diastolic dimension & $72(9)$ & $70(7)$ \\
(SD) (mm) & $9: 3$ & $33: 7$ \\
Men: Women & 7 & 17 \\
Patients with tricuspid regurgitation & 1 & 9 \\
Patients with coronary heart disease & 4 & 16 \\
Patients taking captopril & & \\
\hline
\end{tabular}

the electrocardiogram. We identified the aortic component of the second heart sound from its relation to cusp apposition at the end of ejection on the aortic echogram.

We made the following measurements on the Doppler records (fig 1):

(a) RR interval, $\mathrm{PR}$ interval, and QRS time.

(b) Total electromechanical time $\left(\mathrm{QA}_{2}\right)$-this was measured from the onset of QRS complex on the electrocardiogram to the onset of the first high frequency vibration of the aortic component of the second heart sound on the phonocardiogram. Splitting of the second sound was frequently reversed in patients with left bundle branch block.

(c) The overall duration of mitral regurgitation was measured from the onset to the end of mitral regurgitant signal on the Doppler recording. In the one case with additonal diastolic mitral regurgitation only the systolic component was considered.

(d) Electromechanical delay, as the interval from onset of the QRS complex to that of the mitral regurgitation.

(e) Pre-ejection contraction time, as the interval from the onset of the mitral regurgitation to aortic valve cusp separation marking the onset of ejection.

(f) Left ventricular relaxation time, as the interval from $A_{2}$ to the end of the mitral regurgitation.
From these measurements we derived the two further intervals:

$(g)$ Left ventricular filling time calculated as RR interval minus overall duration of mitral regurgitation.

(h) Aortic ejection time as overall duration of mitral regurgitation minus pre-ejection contraction and left ventricular relaxation times.

We took average values from three beats. Group measurements were expressed as mean (SD). Linear correlation was performed by the method of least squares. The statistical significance of differences between groups was assessed with Student's $t$ test and Fisher's exact probability test as appropriate.

\section{Results}

GENERAL

No difference was found in age, heart rate, and left ventricular size between patients with and without left bundle branch block. Mean PR interval was similar within the two groups, but QRS duration in patients with left bundle branch block was $55 \mathrm{~ms}$ longer than in those without (table 1 and table 2).

CHARACTERISTICS OF MITRAL REGURGITATION IN LEFT BUNDLE BRANCH BLOCK

Mitral regurgitation lasted approximately $100 \mathrm{~ms}$ longer in patients with left bundle branch block than in those without (table 2 and fig 2). To investigate the possible reasons for this we subdivided the period over which mitral regurgitation occurred into three partsnamely, pre-ejection contraction time, ejection time, and relaxation time. Aortic ejection time was the same in patients whether or not they had left bundle branch block. Mitral regurgitation thus lasted longer because the durations of pre-ejection contraction and left ventricular relaxation were both increased, roughly to the same extent.
Figure 1 Continuous wave Doppler trace of mitral regurgitation showing the landmarks identified and the time intervals measured. $A$, Onset of $Q R S ; B$, onset of mitral regurgitation; $C$, aortic valve separation; $D$, aortic valve closure $\left(A_{2}\right) ; E$, end of mitral regurgitation; $F$, onset of mitral regurgitation of succeeding; 1 , duration of mitral regurgitation; 2 , electromechanical delay; 3 , pre-ejection contraction time; 4, aortic ejection time; 5 , left ventricular relaxation time; 6 , total electro-mechanical time, 7 , left ventricular filling time.

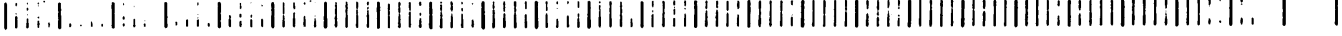

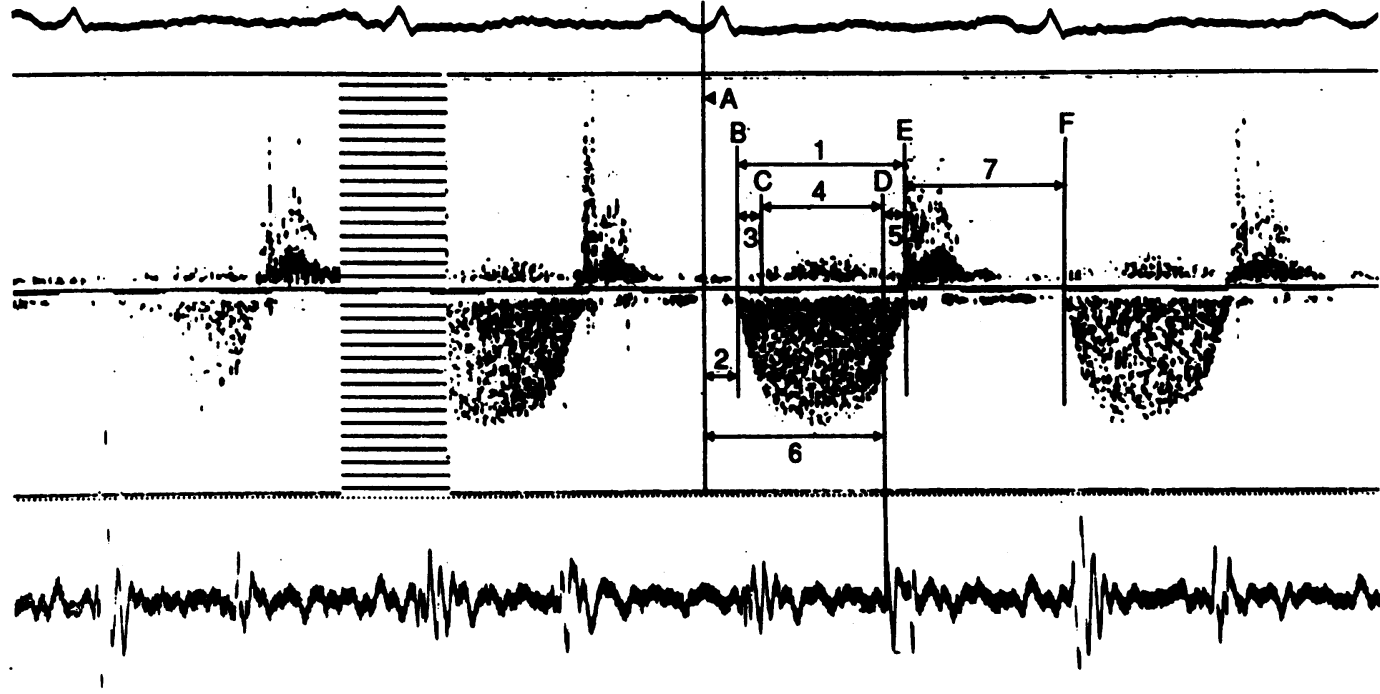


Table 2 Comparison of time intervals between patients with and without left bundle branch block

\begin{tabular}{llll}
\hline Time measurements (ms) & $\begin{array}{l}\text { Patients with left } \\
\text { bundle branch block } \\
\text { Mean }(S D)\end{array}$ & $\begin{array}{l}\text { Patients with left } \\
\text { bundle branch block } \\
\text { Mean (SD) }\end{array}$ & p Value \\
\hline PR interval & $185(30)$ & $175(35)$ & NS \\
QRS complex & $160(30)$ & $105(10)$ & $<0.01$ \\
RR interval & $685(125)$ & $715(130)$ & NS \\
Total electromechanical & $400(70)$ & $380(45)$ & NS \\
Electromechanical delay & $50(20)$ & $70(20)$ & $<0.05$ \\
Mitral regurgitation & $495(90)$ & $390(60)$ & $<0.01$ \\
Left ventricular filling & $190(45)$ & $325(90)$ & $<0.01$ \\
Pre-ejection contraction & $130(40)$ & $70(20)$ & NS \\
Aortic ejection & $230(40)$ & $235(40)$ & $<0.01$ \\
Left ventricular relaxation & $130(30)$ & $80(30)$ & \\
\hline
\end{tabular}

\section{EFFECT OF LEFT BUNDLE BRANCH BLOCK ON LEFT} VENTRICULAR FILLING TIME

Left ventricular filling time was consistently shorter in patients with left bundle branch block although heart rate was similar (fig 3). A limited filling time, less than $200 \mathrm{~ms}^{4}$ was found in eight out of 12 patients with left bundle branch block at a mean heart rate of 88 beats/min, compared with only four out of $\mathbf{4 0}$ without left bundle branch block ( $p<0.001)$, whose mean heart rate was 84 beats $/ \mathrm{min}$.

\section{TOTAL ELECTROMECHANICAL TIME AND}

ELECTROMECHANICAL DELAY

Total electromechanical time $\left(\mathbf{Q A}_{2}\right.$ interval) did not differ significantly between the two groups, but electromechanical delay was consistently shorter by $20 \mathrm{~ms}$ in patients with left bundle branch block (table 2 ).

\section{RELATION TO HEART RATE}

Spontaneous heart rate did not differ significantly between the two groups. The duration of mitral regurgitation, left ventricular filling time, and aortic ejection time all correlated significantly with heart rate irrespective of the pattern of ventricular activation (table 3 ). Preejection contraction time and left ventricular relaxation time, however, correlated with heart rate only in patients with left bundle branch block (table 3), both becoming shorter as heart rate increased. Thus in patients with left bundle branch block the duration of mitral regurgitation was more dependent and that of filling less dependent on $R R$ interval compared with patients with normal activation (fig 3 ). The minor effect of $R R$ interval on the duration of mitral regurgitation in patients with normal activation can be entirely explained by its effect on aortic ejection time (table 3 ).

\section{Discussion}

Functional mitral regurgitation in dilated cardiomyopathy is a common finding. ${ }^{56}$ The regurgitation itself is not usually severe, implying that the effective cross sectional area is small. Flow is thus restrictive and there will be no phase lag between its timing and that of changes in left ventricular wall tension. The mitral regurgitant signal can therefore be used to follow the time course of overall myocardal tension development. To analyse it in more detail we took aortic cusp movement as a landmark to subdivide the total period of mitral regurgitation into three intervals. We refer to the interval from the onset to aortic valve opening as the pre-ejection contraction time. This is followed by aortic ejection time and finally ventricular relaxation time as the interval from $A_{2}$ to the end of mitral regurgitation.

Our study shows that left bundle branch block prolonged mitral regurgitation rather than simply delaying it. The components of mitral regurgitation affected were those before the aortic valve opened and after it closed,
Figure 2 Continuous Doppler echocardiograms recorded in patients $A$ with and $B$ without left bundle branch block showing the difference in overall duration of mitral regurgitation. CT, Preejection contraction time; $E T$, aortic ejection time; $R T$, left ventricular relaxation time; $F T$, left ventricular filling time.

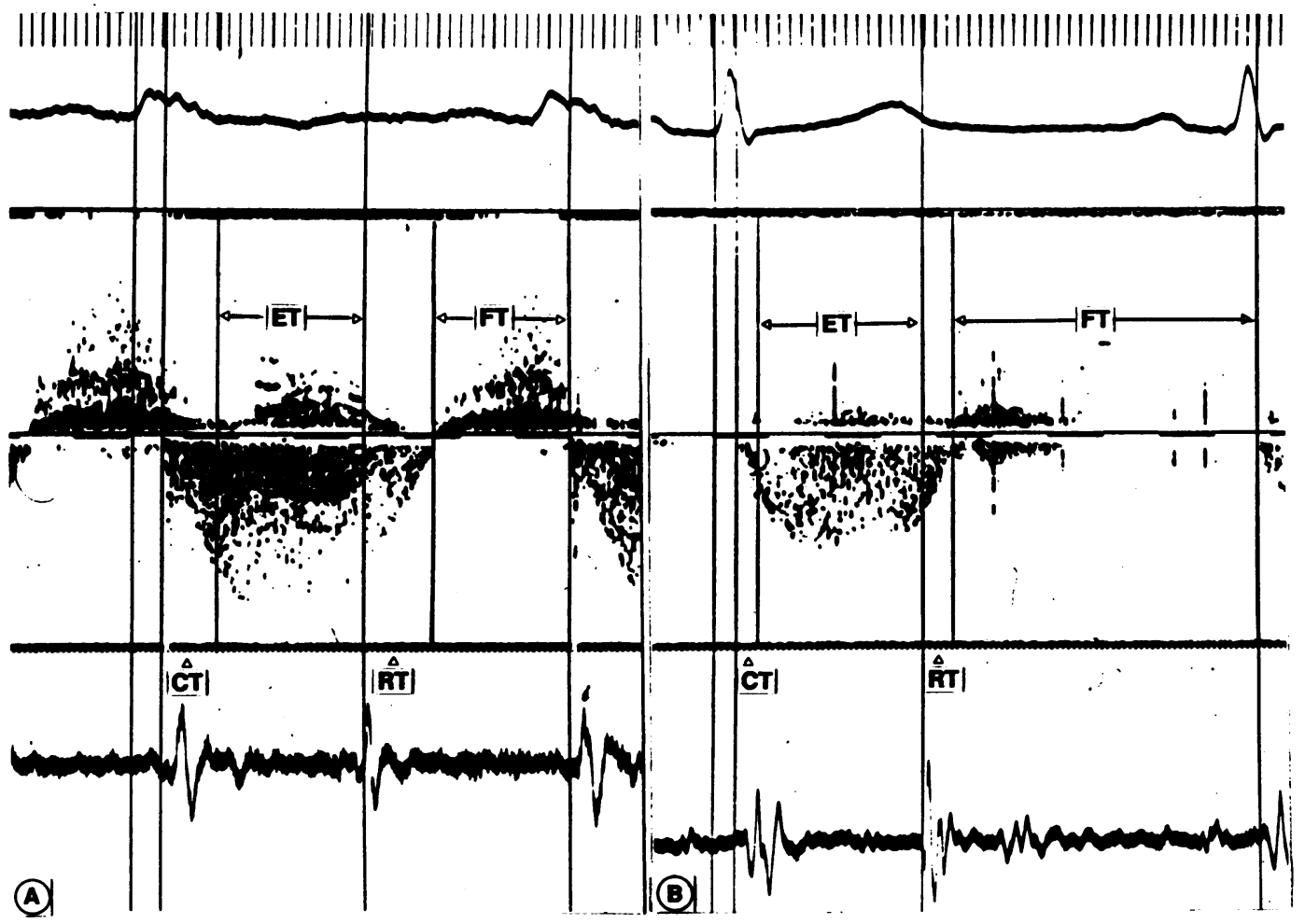




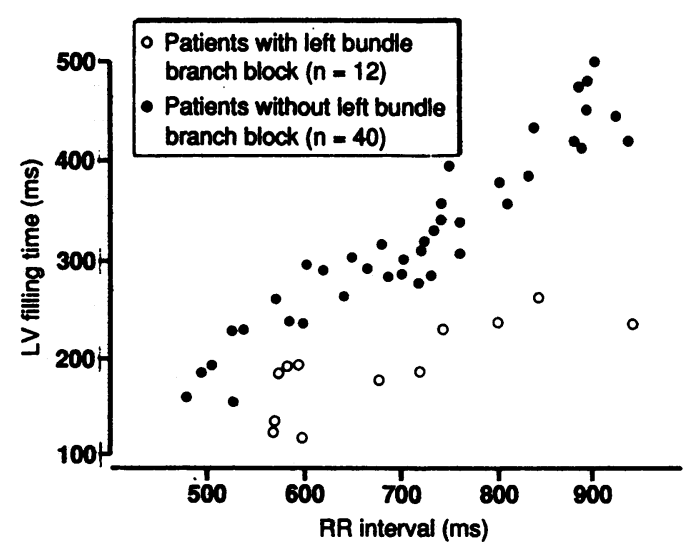

Figure 3 Correlation between left ventricular filling time and $R R$ interval showing the difference between the two groups.

ejection time itself being unaffected. Rather surprisingly, the onset of mitral regurgitation in left bundle branch block was not delayed with respect to that of the QRS complex but actually started earlier. This implied a shorter electromechanical delay. We cannot explain this although it may perhaps have been related to the loss of septal $Q$ wave in patients with left bundle branch block. Thus in our patients, left bundle branch block does not delay the onset of mitral regurgitation as might be expected but makes it last longer - a finding compatible with the idea that left bundle branch block in patients with dilated cardiomyopathy behaves as a peripheral or arborisation block rather than a more central block.

The increase in pre-ejection contraction time and relaxation time could be either because the rates of rise and fall of tension were uniformly reduced throughout the myocardium or because these changes were non-uniform. There is no reason to suppose that a change in activation directly affects the velocity of contraction or relaxation of individual myocytes, so it seems more likely that the mitral regurgitation was prolonged by incoordinate motion of the left ventricular wall. ${ }^{7-10}$ The QRS time was increased by a mean of only 55 ms in left bundle branch block, so this cannot have been the only reason why mitral regurgitation was prolonged by $105 \mathrm{~ms}$. The discrepancy may arise because activation, especially peripheral, may be only incompletely reflected in the QRS complex. Also, abnormal activation may generate further mechanical incoordination as systole proceeds, which also contributes to prolonging the mitral regurgitation.
The duration of the mitral regurgitation also became more sensitive to heart rate in patients with left bundle branch block. With normal activation any change in duration of mitral regurgitation was due simply to the well known effect of heart rate on ejection time. With left bundle branch block this effect was also present, but contraction and relaxation times also shortened as heart rate rose. It seems unlikely that this was due to a direct effect on activation because electrical aberration becomes more rather than less pronounced as heart rate rises. Possibly it had a haemodynamic basis. The progressive rise of left atrial pressure, which must occur when stroke volume is being maintained in the face of a very short filling time, would allow transmitral flow to encroach on the end of relaxation of one beat, and to persist beyond the start of contraction of the next. Filling time of $200 \mathrm{~ms}$ was much more common in patients with left bundle branch block. This explains the apparently different response to heart rate changes in these patients. Also, in patients with left bundle branch block, the rates of rise and fall of systolic atrioventricular pressure difference, as reflected in the mitral regurgitation, were significantly less. This would make the change in filling period per unit change of left atrial pressure correspondingly greater.

Our results therefore suggest that left bundle branch block may have significant clinical effects in patients with dilated cardiomyopathy, independent of cavity size and shortening fraction. When left ventricular activation is abnormal, the overall duration of myocardial tension development is increased by $25-30 \%$. This may itself be important in patients with coronary artery disease as it will increase myocardial oxygen requirements without changing the external power output by the heart. Also, prolonging systole limits the time available for filling. We have previously noted that when filling time drops to less than $200 \mathrm{~ms}$, the form of mitral flow velocity trace changes. ${ }^{11}$ Instead of separate $E$ and $A$ waves there is a single peak, which occurs early in diastole but after the $P$ wave of the succeeding beat. Such a summation filling pattern suggests that stroke volume is being limited by a short filling time. In patients with left bundle branch block a limited filling time was more common than in patients with normal activation and occurred at a much lower heart rate, 85 beats/min compared with 115 beats $/ \mathrm{min}$. The close relation of filling time to heart rate in patients with normal activation

Table 3 Comparison of the effects of heart rate between the two groups

\begin{tabular}{|c|c|c|c|c|}
\hline \multirow[b]{2}{*}{ Variable } & \multicolumn{2}{|c|}{ Patients with left bundle branch block } & \multicolumn{2}{|c|}{ Patients without left bundle branch block } \\
\hline & $\begin{array}{l}\text { Regression } \\
\text { equation }\end{array}$ & $\begin{array}{l}\text { Correlation } \\
\text { coefficient }\end{array}$ & $\begin{array}{l}\text { Regression } \\
\text { equation }\end{array}$ & $\begin{array}{l}\text { Correlation } \\
\text { coefficient }\end{array}$ \\
\hline $\begin{array}{l}\text { Total electromechanical time } \\
\text { Mitral regurgitation } \\
\text { Left ventricular filling } \\
\text { Pre-ejection contraction } \\
\text { Aortic ejection } \\
\text { Left ventricular relaxation }\end{array}$ & $\begin{array}{l}\star Y=95+0.47 R R \\
\star Y=4.3+0.72 R R \\
\star Y=-12+0.30 R R \\
\star Y=-47+0.26 R R \\
\star Y=65+0.23 R R \\
\star Y=-9.7+0.20 R R\end{array}$ & $\begin{array}{l}0.91 \dagger \\
0.96 \dagger \\
0.80 \dagger \\
0.84 \dagger \\
0.71 \dagger \\
0.79 \dagger\end{array}$ & $\begin{aligned} \star Y & =173+0.29 R R \\
\star Y & =126+0.37 R R \\
\star Y & =-147+0.66 R R \\
Y & =28+0.06 R R \\
\star Y & =71+0.23 R R \\
Y & =25+0.07 R R\end{aligned}$ & $\begin{array}{l}0.83 \dagger \\
0.85 \dagger \\
0.94 \dagger \\
0.38 \\
0.77 \dagger \\
0.35\end{array}$ \\
\hline
\end{tabular}

${ }^{\star} \mathrm{p}<0.01$ for slope:

tp $<0.01$ for correlation coefficient. 
provides one explanation of the therapeutic effect of $\beta$-adrenergic blocking agents in these patients. When left bundle branch block is present filling time depends much less on heart rate, which suggests that this approach may not be so effective. It may thus be more appropriate to seek ways to reduce the overall duration of the mitral regurgitation itself. These would have the additional advantage of being effective without reducing heart rate or ejection time in those patients with advanced heart disease.

We acknowledge support from the Brompton Hospital Special Cardiac Fund.

1 Rahko PS, Shaver JA, Salerni R. Evaluation of mechanical events and systolic function in dilated cardiomyopathy: comparison between patients with and without left bundle branch block. Acta Cardiol 1988;43:178-84.

2 Shaver JA, Rahko PS, Grines CL, Boudoulas H, Wooley CF. Effect of left bundle branch block on the events of the
Caver CF. Effect of left bundle branch block on the
cardiac cycle. Acta Cardiol 1988;43:459-67.

3 Baragan J, Fernandez-Caamano F, Sozutek Y, Coblence B,
Lenègre J. Chronic left complete bundle-branch block. Phonocardiographic and mechanocardiographic study of 30 cases. Br Heart $J$ 1968;30:196-202.

$4 \mathrm{Ng} \mathrm{KSK}$, Gibson DG. Impairment of diastolic function by shortened filling period in severe left ventricular disease. Br Heart J 1989;62:246-52.

5 Keren G, Katz S, Strom J, Sonnenblick EH, LeJemtel TH. Noninvasive quantification of mitral regurgitation in dilated cardiomyopathy: correlation of two Doppler echocardiographic methods. Am Heart J 1988;116: 758-64.

6 Strauss RH, Stevenson LW, Dadourian BA, Child JS. Predictability of mitral regurgitation detected by Doppler echocardiography in patients referred for cardiac transechocardiography in patients referred for

7 Gibson DG, Prewitt TA, Brown DJ. Analysis of left ventricular wall movement during isovolumic relaxation and its relation to coronary artery disease. Br Heart $J$ 1976;38:1010-9.

8 Kreulen TH, Gorlin R, Herman MV. Ventriculographic patterns and hemodynamics in primary myocardial disease. Circulation 1973;47:299-308.

9 Chen W, Gibson D. Mechanisms of prolongation of preejection period in patients with left ventricular disease. Br Heart J 1979;42:304-10.

10 Chen $W$, Gibson D. Relation of isovolumic relaxation to left ventricular wall movement in man. Br Heart $J$ 1979;42: ventricus.

$11 \mathrm{Ng} \mathrm{KSK}$, Gibson DG. Relation of filling pattern to diastolic function in severe left ventricular disease. Br Heart $J$ 1990;63:209-14. 